\title{
Individual Experiences and Life Satisfaction of Informal Elderly Caregivers in Poland: A Study Based on In-depth Interviews ${ }^{2}$
}

\begin{abstract}
The Polish population is aging, generating a huge need for care, which for cultural reasons, and as a result of limited availability of professional care is predominantly the responsibility of family. In order to explore the experiences of informal elderly caregivers in Poland, 20 in-depth interviews were conducted. The aim was to understand what characteristics of the caregiving situation are meaningful for caregiver Subjective Wellbeing $(\mathrm{SWB})^{3}$ and what important, valuable beings/doings in terms of the Capability Approach (CA), caretakers cannot achieve because of their caretaking role. The study also aims at exploring what public policy tools/measures are perceived as those that could positively affect SWB. The results show that, the subjective evaluation of SWB is not only highly related to factors such as burden of care, characteristics of the care recipient, caregiver support and/

1 Correspondence: Wydział Nauk Politycznych i Studiów Międzynarodowych, Uniwersytet Warszawski, ul. Krakowskie Przedmieście 26/28, 00-927, Warszawa, Polska; email: klaudyna@hotmail.com

2 The article presents partial results of the doctoral dissertation entitled "Subjective Wellbeing and Provision of Informal Care to Parents - Recommendations for Public Policy Formation" written under the supervision of dr hab. prof UW Anna Kurowska.

3 Used interchangeably with life satisfaction.
\end{abstract}


or time spent caring but also on limitations that caregiving imposes on the ability to achieve valued functionings. Furthermore, while many characteristics of the caretaking situation are perceived by caregivers as negatively affecting their SWB there are also aspects which can increase their SWB. Finally, people have preferences when it comes to the types of help they want and these preferences are dependent on their individual situations.

Key words: subjective wellbeing, valued functionings, senior policy, informal elder caregivers

\section{Introduction}

The demographic setting across all OECD countries has changed drastically over recent decades and due to the increasing life expectancy and low fertility rates populations are aging. Poland belongs to the fastest growing aging societies within the European Union and it is estimated that by 2060 the share of people aged over 65 years will reach $45.3 \%$ of the entire population (European Commission, 2015). This generates a huge need for care. For cultural reasons, and as a result of the limited availability of professional caregivers, the predominant form of care for elders in Poland has been and still is, care provided informally by family members (Bakalarczyk, 2018). In Poland, there exists a well-established norm that it is the family who should provide care, especially to parents. This makes the current senior policy regime in Poland familialism by de-fault, a regime characterized by limited benefits and other types of limited support for informal caregivers (Saraceno \& Keck, 2010). The availability of public replacement support in the form of in-home and institutional care services, is hardly accessible and very scarce. Market solutions are not only expensive (even if co-financed), but also hard to access (Krzyżowski, 2011; Bakalarczyk, 2018). What this phenomenon means for Poland is that there is and will be a growing population of informal elderly caregivers who lack support, and their wellbeing should be of particular interest to policymakers when designing long-term care policies (Wizner et al., 2012).

While there exist studies, which focus on the SWB of informal caregivers there is a scare amount of research showing the differences in SWB amongst people who are burdened with informal care and those who are not. The relationship between informal caregiving and caregiver SWB has been found to depend on personal characteristics and situational factors (van den Berg et al., 2014; Rafnsson et al., 2017; Verbakel et al., 2018). Most studies suggest that informal caregiving negatively impacts SWB of caregivers (Lacey et al., 2018).

In Poland a few studies have been conducted in the field of caregivers and their life satisfaction, such as life satisfaction resulting from caregiving role (Grochowska, 2014; Stojak et al., 2019) or quality of life of informal caregivers (Perek-Białas \& Stypińska, 2010; Ślusarska et al., 2019). There exists no literature however, referencing SWB strictly (as measured by the SWLS). There is also a lack of studies providing detailed insight into the personal experiences of informal elderly caregivers, their opinions about the most desirable public policy solutions and how these tools would help increase caregiver SWB. 
The present study aims at addressing the above-mentioned gaps and exploring the characteristics of individual caregiving situations and how they are (perceived) as related to SWB of caregivers. The aim is also to understand people's experiences with informal caregiving and how caregiving interferes with the ability to achieve other doings and beings which caregivers value. Furthermore, the study aims at exploring what kind of support informal caregivers believe would enable them to achieve higher SWB and based on their experiences, formulate guidance on the kind of support informal parent's caregivers require from public authorities.

\section{Theoretical Framework}

The analysis of the research done in this study is grounded in the CA originally proposed and developed by Amartya Sen (Sen, 1983; Sen, 1999) and recognised in economics literature as an alternative to mainstream income-based measures of wellbeing (Robeyns, 2006). Sen (1999) argues that human life may be seen as a set of interrelated "beings and doings" called "functionings" and the concept of "valued functionings (VFs)" reflects the various beings and doings people value. Some examples of valued beings are being educated, being healthy, being well-nourished, while working, travelling and engaging in leisure is considered as valued doings (Kurowska, 2018). Together these doings and beings are what makes a human life valuable. Capabilities on the other hand, according to Sen (1999), are real opportunities a person has to achieve desired, VFs. Therefore, capability is a sort of a freedom to achieve various lifestyles. In theory, the more capabilities people have to achieve VFs, the better.

In the present study, the experiences of informal parental caregivers are examined in terms of their ability (capability) to achieve VFs. The questions are structured in a way which allow the author to identify respondent's VFs, whether they are able to achieve them and if not, whether providing informal care to their parents is an obstacle in being able to achieve them. The study also provides insight into whether there are VFs in caregivers lives which result from their caregiving role.

\section{Method}

20 in-depth, semi-structured interviews with informal caregivers to parent(s), parent(s) of partners/spouses or parent(s) in law were conducted. 5 of the respondents were men and 15 were women, all of the participants provided informed consent to participate in the study and to be recorded during the interview. The author used the snowball sampling method to reach respondents through personal contacts, social media (forums/groups), and Stowarzyszenie Syntonia ${ }^{4}$. The interviews took place between mid-November 2019 and mid-March 2020. To determine the size of the sample the principle of saturation was

${ }^{4}$ NGO which provides therapy, consultations and workshops to elderly, retired people as well as their caregivers and families in Warsaw. 
used which is defined as a point at which further collection of data no longer offers new information and no longer sparks new theoretical insights (Mason, 2010).

The first part of the interview consisted of the Katz Index (KI) of Activities of Daily Living (ADL), which describes a person's level of independent functioning (Katz et al., 1970), and the Lawton Instrumental Activities of Daily Living (IADL) scale (Lawton \& Brody, 1969), which assesses independent living skills, as well as, the 7-point Satisfaction with Life Scale (SWLS) which measures SWB (Diener et al., 1985). The second part consisted of open-ended questions and allowed respondents to freely express themselves based on their experiences, knowledge, feelings and understandings. The open-ended questions where divided into three parts 1) own experiences 2) subjective perception of life satisfaction and 3 ) policy solutions. The first part explored the history of care and the realities in which the carer of the elderly parent lives. Study participants were asked to describe the tasks they perform in relation to care and the why, where and how of caring. Respondents were asked whether the they received any help from third parties and what their relationship is with the care recipient. They were asked to identify the biggest problems associated with caring, whether providing care negatively affects any aspects of their lives, and if there are any things that they cannot do as a result of their caregiver role which would raise their SWB.

The second part focused on the subjective perception of SWB. Respondents were asked if their role as an informal parent's caregiver negatively affects their SWB, if it negatively affects any other aspect of their life and if there are other things that negatively affect their SWB. Respondents were also asked if there is anything in their current caregiver role that positively affects their SWB. In the last section participants were asked about their experiences and expectations in terms of senior policy tools and outside support. Respondents were asked to describe an ideal solution of help/support, which would make caregiving less of a burden and would allow them to achieve higher SWB. Information provided during the interviews was organized using thematic analysis, a technique that allows to identify patterns and themes in available data (Braun \& Clarke, 2006).

Results

\section{Time Spent Caring and History of Care}

The amount of time spent providing care to parents varied depending on individual situations. The ability for respondents to answer exactly how much time they spend providing care to their parents often depended on whether or not they lived with the care recipient. It was also correlated with the burden of care, as well as related to the health characteristics of the care recipient and the amount of people (or institutions) simultaneously involved in the care situation. Respondents were grouped into 3 categories. In the first group were those who would travel to their parents a few times a week (about 10-15 hours per week). In the second were those who lived with their parents and provided occasional help and in the third group were those who spent all their free time and resources providing care. 
Respondents in the first group were better able to provide an estimated amount of time spent on care each week: “...we take turns going to my mother's house with my brother about 2-3 times a week for a few hours....” (R7/F41). They found care provision to be a separate task with a timeframe which was somehow structured and which they treated as part of their weekly routine. In this group the distance from the caregiver's place of residence to the place of residence of the care recipient was important. Although the majority of respondents lived within the same city, one had to travel $125 \mathrm{~km}$ to provide care to her mother. She mentioned that: "...every weekend for the past 6 years I have been getting into my car and driving for over an hour to help out my mom with some responsibilities at home, do some shopping for her, prepare her for the upcoming week, I have to do this, it takes up all my free time, especially the distance..." (R3/F52). It is plausible to assume that many informal parent's caregivers will be in similar situations especially with the current trend of people migrating from rural to urban areas for work/education.

In the second group, people had a hard time determining how much time they spend on care provision. For these respondents the distinction between their regular responsibilities and more specifically responsibilities associated with providing care to an elder was slightly more blurred: "...I guess maybe a few hours a day, we live together so when there is something they can't do I do it but I don't know... it's really not easy to say..." $(R 2 / M 50)$. The respondents indicated for the most part, that of course there were things they had to assist their parents with and they were able to name these things however, it was difficult for them to give a number of hours or amount of time a week they were actually providing care.

In the last group, respondents most often said that care was a full time, round the clock activity: "...it is full time care, all day, all night even though my sister helps and we have 2 private caregivers helping out...” (R15/F57). The timeframe of their caretaking role wasn't limited to engaging in physical activities related to care but included also, constant awareness and alertness, worrying about the wellbeing of their care recipients and monitoring their activities: "...even when I'm not providing care per say, I have to be alert and make sure she doesn't run away...” (R20/F45). Within this group of respondents caretaking wasn't an additional responsibility; caretaking was a life situation affecting their lives in every aspect.

In terms of the length of time providing care to parents, respondents were grouped into two categories. The first consists of those who could indicate a specific life event that was linked to the onset of their care provision such as an injury, medical condition or other: "...we started to provide care to my mother when my father passed away 9 years ago...” (R16/F54). The second, consisted of those who said that their role as caregiver emerged gradually. Respondents whose caregiver roles were not elicited by a specific event had a more difficult time providing an exact time frame of when care provision started: "...more seriously for the past three years but before that also just more sporadically..." (R11/M31). Respondents in both groups often noticed that naturally, as their parents became older, they required more attention and help. 
Both when it comes to the time spent caring and the history of care, many respondents mentioned that care provision depends on current physical and psychological states that their parents go through. Depending on their current condition they require either more care and assistance or less: "... sometimes my dad calls me every day and asks how to do the simplest things or wants me to come and help and sometimes he even says there was no need for me to come..." (R4/M50). There were periods when care recipients were able to do things on their own and were able to mutually enjoy the time spent with their caregiver: “...sometimes on better days when her memory is better we spend some nice time together like mother and daughter..." (R9/F55).

\section{Characteristics of Care Recipient and Burden of Care}

An important aspect in analyzing informal parent's caregiver situations was the physical and psychological characteristics of the care recipients as well as the (resulting) burden of care. Burden of care refers to the impact that care provision has on the physical, psychological and social aspects of the caregiver (O'Neill \& Ross, 1991). The former was what often made care excessively difficult. Additionally, both the burden of care and care recipient characteristics run in parallel with each other and with the amount of time spent on care. When they are considered together they become very significant in terms of attitudes of respondents.

In terms of the characteristics of the care recipient there were two groups 1) those providing informal care to parents with no symptoms of dementia and 2) those providing informal care to parents with symptoms of dementia resulting in a decline in memory, language, problem-solving and other thinking skills that affect the ability to perform everyday tasks. Overall attitudes of respondents were much more negative when their parents were lacking the ability to normally interact with their surroundings. This was true even when respondents where providing care to people who were severely physically disabled but still mentally aware.

Respondents within the first group, who were providing care to parents (even if they required 24-hour supervision) but didn't show symptoms of dementia often seemed less affected by their role as caregiver and it had a smaller effect on their SWB when compared to the second group. They considered themselves lucky because they were able to sometimes leave their parents alone (if they lived together) and take care of their own matters or postpone/delay a visit (if they didn't live together) without worrying about their care recipient: “...at least my mom is aware of her surroundings and mentally healthy and I can leave to go to work...” (R17/F60). Respondents, often said that they would prepare things for their parents, leave them alone for a period of time, and attend to their other responsibilities: “...I work full time, so I prepare things as much as I can for the day and then she stays alone...” (R19/F41). Furthermore, elders who did not have dementia were able to maintain hobbies/past times such as reading, watching television, solving puzzles etc. meaning they could organize some of their free time and as a result not require full 
time attention: “...my mom reads, solves puzzles, watches TV shows, then I don't feel bad that she's alone...” (R1/F36).

Respondents within the second group, caring for parents with dementia, often mentioned that they felt as if they were prisoners of their situation because they were not able to leave their parents' side even for a second: "...it's not just care that is tiring - I feel like a slave...” (R15/F57). Dementia causes elders to be out of touch with reality and leads to troublesome situations. Respondents feared that their care recipients would do something endangering themselves or their surroundings: "...my mom is starting to forget things, she once hid money and couldn't find it, once she left the door open to her house and once she even left the gas stove on...” (R5/M68). Caregivers mentioned that this was the most difficult part of their caretaking role because these situations caused them to have to be constantly alert and to feel helpless. Elders with dementia were no longer able to maintain hobbies and would spend their time talking nonsense to their caregivers who felt obligated to maintain some type of interaction which was very draining: “...you know, my mom is just constantly talking nonsense, its tiring but I feel bad but it's all day, I wish I could find her something to do to keep busy..." (R15/F57). On the one hand respondents were tired, felt enslaved and discouraged but on the other hand they didn't want to ignore their demanding parents which caused them even more anxiety and stress. Additionally, patients with dementia often elicited aggressive behaviour and were likely to behave in ways that were unpleasant towards their caregivers. One respondent said that her mother often accused her of stealing money from her and that sometimes she would curse at her and call her names in front of other people: "...I am mentally exhausted, my friends are out enjoying life, sailing and I was being called a bitch, in stores at home, she was aggressive..." $(R 8 / F 32)$. Another respondent said that often her mother is aggressive vulgar, and/or cries for no reason which makes her feel completely helpless and unhappy: “...once at 1 am my mom woke me up and told me to give back something, I don't even know what and she then told me to get the f*** out of her house, I just went out on the balcony and cried..." (R6/M63).

The more care and the harder and more time consuming the activities related to care, the more time and other resources caregivers have to sacrifice and the larger the burden of care. Respondents who had parents whose physical or mental health conditions were worse had a higher burden of care. The burden of care described by respondents can also be visibly related to scores on the ADL and IADL. In general respondents who had parents scoring lower on either or both of the ADL and IADL scale had more responsibilities, spent more time and effort providing care and felt more burdened by the situation. More so, whether people had parents whose scores were lower on the IADL (activities such as paying bills, preparing food, dealing with money etc.) or on the ADL (activities such as help eating, showering, using the toilet etc.) didn't seem to matter because each situation had its own obstacles affecting caregivers' lives. Both physical and mental limitations differently but equally influence the burden of care.

Aside from mental health and dementia there is also the case of those respondents caring for parents with low physical mobility levels. Female respondents (especially if they were also older themselves) who were in a situation where caregiving meant a lot of 
physical labour often mentioned the strain on their own physical health exerted by care: “...my mom doesn't weigh little, sometimes after the whole day of helping her get up or move around I feel physically exhausted...” (R15/F57). Elderly parents who were incapable of performing ADL activities required the most physical assistance, were often overweight and respondents had to use a lot of physical strength to help them perform activities.

\section{Caregiver Support}

Another significant theme which emerged was related to the support caregivers were receiving and who they could or couldn't count on in their daily care related activities. In terms of caregivers' attitudes, most important was whether or not the caregiver could count on other family members for support. Respondents were grouped into two categories 1) those who took turns caring for their loved ones and 2) those who said they couldn't count on any help and they felt abandoned in their caretaking role. Furthermore, while there were two groups of respondents those who mentioned that they received outside, professional help and those who didn't, the former group seemed to be more critical about this help than thankful for it.

When it comes to familial support the first category encompassed those informal caregivers who had siblings, spouses and/or other family members who also provided care and took turns with responsibilities related to caretaking. Almost all the respondents in this group mentioned that they were very thankful to family members, especially siblings, for sharing the care responsibility both physically, emotionally but also financially: "...we take turns caring with my sister, sometimes my sister takes my mother sometimes she is with me, we also have a brother... he makes a lot of money so he helps out financially..." $(R 9 / F 55)$. Respondents mentioned that they are lucky enough to be able to have time for their own things when other family members take over and that this is extremely important to them. They often mentioned that the care responsibility was equally shared, that they supported each other, and somehow planned things in a way so that everyone could still manage to do things that were important to them: "...twice a week my brother and his wife take my mother home for a few days, then I can relax go away somewhere...” (R20/F45).

In the second group of respondents were those who didn't have any support from family members. Respondents in this group were often more negative and bitter about their situation: "...my brother's wife is sick so he can't help me and never does, sometimes he comes over for coffee but that's not help...” (R12/F63). They often said that there was no one they could count on if they needed help themselves.

When it comes to institutional/private support and help/care two categories emerged 1) those who took advantage of some form of outside help and 2) those who didn't. In most cases those respondents who took advantage of private/institutional help in the form of formal and/or paid caregivers were caring for parents who had more severe disabilities and required more extensive care. They mentioned they were not completely satisfied with the available services because they were either inadequate, hard to organize or generated additional work for the caregiver: "... we have a formal caregiver from the municipal social 
welfare centre but their hourly limit of work is already exceeded by 2000 hours and they can only come twice a week for 2 hours but each time we have to fill out a million papers... all this is an additional burden when I don't even have time to sleep I don't have time to go back and forth with paperwork..." (R16/F54). Furthermore, care recipients had a hard time accepting and trusting outside help which created conflicts: "... we had two caregivers but my dad couldn't get along with either one..." (R4/M50). It wasn't as obvious as in the case of help from other family members that those respondents hiring outside help were more relieved and less stressed and overwhelmed by their caretaking role.

Respondents in the second group also mentioned that professional, outside help was difficult to find and organize and respondents were sometimes wary of letting strangers into their homes: "...finding a private caregiver is very hard, when they hear where we live they all say no this is too far for me... there is no support from outside from the government, everything involves going out, calling, waiting, forms, paperwork, fill out papers...” (R17/F60), "...I am scared to let in a stranger into my home..." (R20/F45). Aside from the difficulties associated with finding appropriate outside help in this group, finances seemed to be a very important aspect. Respondents often mentioned, that as much as they would like to hire outside help they could not afford it: "...my mother's pension is very low and these type of solutions are very expensive, we can't count on any financial support...” (R7/F41). Some claimed that outside help was non-existent (usually referring to public help) or that they didn't know where or how to look for it: “...public institutions don't exist, there is a complete lack of them...” (R8/F32). One respondent said that while Day Welfare Homes were available in her area she didn't have the resources and time to transport her mother there every morning.

\section{Caregiving Life Satisfaction and Things People Value}

Respondents were directly asked whether caregiving affects their SWB. When asked about if caring for their parent affects their life satisfaction 10 respondents answered that care does not affect their life satisfaction. The remaining 10 who mentioned that caretaking did affect their SWB had parents who scored lower on the ADL and IADL scales; most of those caring for parents with dementia were in this group. For the group of interviewed caregivers, it can be seen that both in the case of ADL and IADL scores there is a weak positive relationship between SWB levels and scores on both ADL and IADL scales (the higher the score on the IADL/ADL the more independent the care recipient). All respondents were eager to explain their answers and regardless of whether, they said that caretaking affects their SWB or not, they provided similar explanations for which parts of caretaking and why it affects their SWB. The following themes emerged explaining why and how caretaking negatively affects SWB: 1) lack of time, 2) physical and emotional strain, 3) lack of support and 4) lack of available access to and quality of health and social care. While some respondents were hesitant to explicitly say that caretaking affects their SWB the role of being an informal parent's caregiver almost always negatively affected some area of their life. 
The most common explanation of why/how caretaking affects caregiver SWB was related to a general lack of free time. All respondents, at some point during the interview, mentioned that (free) time was something that was missing in their lives: “...the help and care is not the problem the time it consumes from everything else is..." (R3/F52). The amount of time spent providing care, which resulted in less time to do other things, had an impact on respondents' SWB especially if they were the only ones responsible for care provision. This was especially true for those respondents who provided 24-hour care; they mentioned that even when they were not doing care related activities they were still busy supervising their parents. Often respondents had their own families which they felt they were not paying attention to as a result of caring for their parents: "...I don't have time to see my grandchild and he is growing so quickly..." (R16/F57).

The fact that many informal parent's caregivers pointed to lack of time as a main factor contributing negatively to their SWB was also important because it meant that people were not able to do things that they valued doing. When asked about the things they were not able to do because of caretaking that could improve their SWB many mentioned things like caring for their own basic needs: "...I don't even have time to go to the hairdresser...” (R17/F60), participating in sports: “...for sure I would love to go back to sports, tennis, basketball I used to do a lot of sports and now I do not have the time..." (R4/M50), being able to work: "...I would go to work if I could, I always worked and I liked being busy, plus financially it would be helpful but I can't..." (R6/F63), being able to go on vacation: "...currently I do not have the time to go on a trip or vacation while before I was able to do these things..." (R19/F41), being socially active: “...I can't go out with friends, to the theatre to a restaurants because over the weekend I have to help and organize everything..." (R3/F52), caring and monitoring own health: "...I don't have time for my health, I used to be very interested in healthy cooking, living...” (R6/F63) and even sleeping: “...I am not sleeping because I have to watch my mom...” (R15/F57). The overall lack of time related to informal caretaking affects the ability of people to do other things they value.

The second theme which emerged was the physical and emotional strain related to care taking. As mentioned earlier, this was related to the burden of care as well as the characteristics of the care recipients. Respondents, especially those caring for parents with dementia but not only, often mentioned that while the care alone was not really affecting their SWB their elder parents were often very demanding emotionally and this emotional strain was what affected their SWB: “...I am very tired mentally tired all the time, too tired to enjoy things..." (R8/F32). The additional amount of work related to performing care activities was also considered by many to be physically straining. Respondents often mentioned that after a whole day of work or week of care they no longer had the physical or mental energy to be able to enjoy other things in life.

The third emerging theme was the lack of support from family directly related to caretaking but also weak family ties in general. Respondents mentioned that there was no one they could count on for help which made them feel abandoned and affected their SWB: “...lack of solidarity in the family and lack of support from my husband, he doesn't want my mom to move in..." (R13/F62). Some respondents who mentioned that caretaking 
wasn't negatively affecting their SWB realized that the reason for this was because they could count on other members of their family and care was provided in turns: "...no caretaking does not affect my life satisfaction negatively because I share it with my brothers and husband..." (R7/F41). Two respondents mentioned they had other family related problems which affected their SWB more than anything else.

The last emerging theme was the lack of available access to and quality of health and social care. Many individuals felt abandoned, frustrated and helpless and this affected their SWB. Respondents mentioned that the amount of paperwork was overwhelming and time consuming, that there was a lot of uncertainty and lack of information about what resources are available and how to take advantage of them. They felt that the government and public institutions which were supposed to resolve social problems and care for citizens where not doing anything to help: “... so what if there are available tools, I don't know what they are nobody tells me, I feel overwhelmed when I have to go to any public institution, they have never helped me it is really frustrating..." (R18/M59). Individuals mentioned that the options and tools available theoretically were in practice very inadequate in terms of their needs and the needs of their care recipients: "...my mother used to attend day welfare homes but it was hard for us to get her there, maybe if some transport was provided, she was on a wheelchair...” (R8/F32). Many respondents mentioned that health care services were not adequate and medical personnel was not properly trained to deal with elders, especially those with dementia: "...one time we had to call an ambulance and they came and took my mother and the paramedic was asking my mom about the medications she takes, she has no idea what she takes because she has Alzheimer's...” (R9/F55).

Lack of support from the social system and health care system was a very popular topic amongst respondents when asked about SWB. On top of being rather negative about the services or lack of them something equally important mentioned by respondents was that they had no source of information and training on how to perform caretaking responsibilities. One respondent mentioned that the most overwhelming aspect of caretaking affecting his SWB is that he has no idea what he is doing: “...the worst is that I do not know many things, I don't understand things, a caregiver has to know how to provide care, I was never in such a situation so how do I know how to act and manage and help my mom..." (R5/M68). While this respondent was lucky enough to be able to attend meetings and trainings organized by Syntonia these types of services are not common nor offered elsewhere. Respondents mentioned that finding outside training/workshops could improve their SWB but neither churches, nor public or private institutions offered any such help.

In terms of how caregiving affected respondents three groups of respondents emerged 1) those who didn't mention any positive effects of caregiving on their SWB, 2) those who said that caring was their responsibility and this role made them feel needed and fulfilled and 3) those who said that the social aspect of caring and time spent with their care recipients actually increased their SWB.

In the first group, those who didn't consider their caretaking role to have any positive impact on their SWB, were respondents caring for parents with some sort of mental condition and/or dementia. This can be attributed to the fact that respondents in this 
situation experience little or no meaningful social interaction with their care recipients: "...when something is happening in your life you want to go and talk about it with your mom and I can't do that I don't have her support, actually it's her I usually need to complain and talk about..." (R8/F32). Furthermore, the strain related to caring for an elder with dementia seemed to overshadow even feelings of fulfillment related to care which were mentioned in the second group of respondents.

In the second group of respondents' people often mentioned that care provided to their parents (and the parents themselves) was something that they were responsible for and that they felt complete and fulfilled by doing so. Respondents in this group mentioned that their SWB is higher because they are confident and aware that they are doing their part and fulfilling their responsibilities. They felt needed: “...it makes me happy that I feel needed...” (R5/M68) and felt that their loved ones are being properly cared for: "...important is realization that the person that I am caring for is safe and doesn't need anything...” (R1/F36).

Finally, in the third group, were those who found satisfaction in the social ties created within their caretaking situation. Respondents noted that caring for their parents attributed to a higher SWB and/or positive feelings. While on the one hand, caretaking limits the amount of time and resources for other family members, on the other, it can bring families together. The physical state of the care recipient is not very important in this matter, in order for this time to be meaningful care recipients have to be in good mental state. Respondents often mentioned that while providing care to their parents was tough in many ways they also enjoyed spending time with their parents: “...last week we had grandmothers' day and the whole family came it was very nice, we laughed and talked..." (R17/F60). They were able to catch up on many things that they didn't have time for before, and their parents could still comfort them and provide emotional and social support if they were going through difficult times: “...my mom is a very warm person and I can talk to her about my problems...” (R3/F52). One male respondent who went through a difficult divorce felt that caring for his parents was what keeps him hopeful and alive: "...it increases my life satisfaction, I feel needed, I have someone to talk to, my mom is the only ones I have left, I don't know what I will do when she is gone...” (R5/M68).

\section{Desired Public Policy Solutions}

Respondents were asked to consider their personal situations and provide "ideal" support which they would want and which would increase their SWB. All respondents mentioned that they would (to at least some extent) entrust care to someone from the outside be it public care or private care. Given their experiences respondents were also able to provide many different tools and resources (benefits, in-home help/assistance, transport logistics, social support services etc.) which would help them with their caretaking role and make caretaking less of a burden.

Respondents who weren't already receiving some form out outside help from family or professional caregivers always mentioned that they would be willing to hire/accept 
outside caregivers. This remained true even for respondents who believed that 24-hour institutional care was completely out of the picture: “...my mother would absolutely not agree to all day institutional care unfortunately but I would love to be able to even pay and hire a caregiver..." (R10/F60). While respondents mentioned that ideally these caregivers should be specialized in caring for elders (provide rehabilitation services, activate the elderly, encourage physical activity etc.) for the most part they would be satisfied simply if a professional/private caregiver would provide them with time away from caretaking, time that they could use for themselves: "...it would do a lot for me if I could have some time off and during that time would come someone who could help with rehabilitation or simply care for a few hours..." (R1/F36). Respondents also mentioned that they would gladly take their parents to Day Welfare Homes but they either weren't available or participation was hard to organize: “...it would be good to be able to give elders away for the day but this doesn't exist or at least I haven't been able to find such a solution...” (RR19/F41). Although many respondents would entrust care to outside helpers this was not always possible. For the most part problems associated with receiving help from in-home caregivers was related to the fact that a good reliable, trustworthy caregiver was hard to find and relatively expensive.

5 respondents said that they would definitely, immediately place their family members in an institution; 4 of them had parents who had different symptoms of dementia. For two reasons this was not possible 1) finances and 2) parents not willing to be moved. Respondents mentioned that 24-hour care facilities were extremely expensive even for those people who were relatively well-off and for those who could share the cost with other family members: "...I would love to be able to afford an institution or for it to be accessible...” (R13/F62). Respondents also mentioned that their parents did not want to leave their house and that they couldn't forcefully place them in an institution: “...my mom would never go to such an institution, how can I force her?...” (R18/M59). Although overall respondents were less likely to want to take advantage of 24-hour institutional help many mentioned that they were aware that their parents were getting older and that with time they would require more help and a time could come when they would prefer/require 24-hour institutional care facilities to be made available because they would no longer be able to provide care for various reasons: "...I realize that one day I might have to give her away, I simply won't have the strength to continue although I hope not...” (R3/F52). While overall respondents are not likely to give their parents away to care facilities and want to provide care as long as they can (of course ideally with the support of others) they also realize that there is only so much they can do and that they may face a situation where this type of care would be most suitable, meaning that it should be accessible.

Respondents provided interesting and informative ideas, solutions and tools which should be made available to increase their SWB. The results can be grouped into five categories 1) time-off care (solutions providing alternative care for elders which in result give the caregiver time do attend to other responsibilities or rest), 2) caregiver social and educational support (tools aimed at providing workshops, training and knowledge about providing care for caregivers), 3) procedural solutions (simplifying procedures 
necessary to receive social and medical help), 4) help/activities for elders (most diverse category including different tools and solutions aimed improving/monitoring/managing the health and wellbeing of elders, creating activities for them and helping them with daily functioning) and 5) financial support (funding of medication, rehabilitation, in-cash benefits etc.).

In the first category (time-off care), the most popular discussed option to increase SWB of caregivers was having easy reliable access to trained, educated and reasonably priced, professional in-home caregivers (provided either by the private or public sector). Almost all respondents agreed that this would definitely help informal parent's caregivers and should be offered: "...in-home caregivers are the ideal solution because they can come and take a little bit of weight off of me..." (R11/M31). Respondents mentioned that in-home caregivers would allow them to better plan their days and provide them with more time for other responsibilities or for rest. Respondents however, also mentioned that availability of caregivers would be helpful even if these caregivers only helped out with tasks not directly related to care such as help with shopping: “...it would be helpful if someone for example would do our shopping or bring us something like medication because with the rest of the care I can manage..." (R7/F41). Finally, respondents often mentioned that this type of help would not necessarily have to be provided according to any specific schedule but rather that in times of need caregivers would be available on an on-call basis: "... an on-call caregiver, if you are in an emergency situation, you need to get something done she comes and helps you out or takes over...” (R10/F60). As an alternative to in-home caregivers' respondents also mentioned that they would be willing to use the services of day-care centres for elders. Essentially, for these respondents it was important to be able to have a place where they could leave their parents, usually for the duration of the work day or for them to be able to attend to other responsibilities or simply rest: “...I think ideally there should be some daytime institution where elders could go so that caregivers would be able to know they are cared for in that time..." (R14/F55). While respondents did mention that they were aware of the fact that these places existed they said that they should be more available and more importantly that specific activities must be put in place to activate and interest elders. Another preferred solution, within the first category was respite care, which respondents agreed was very important. Respondents mentioned that while caring was not always a very difficult task it was definitely a time consuming, long-term activity. They were often not only providing care to parents but also caring for their children, working professionally and keeping the household running. This meant that they were unable to enjoy time off and they were not able to go away on vacation: “...we used to travel a lot but now it's impossible I wouldn't mind and I don't think my mother would be upset either if we left her with someone for two weeks or so and go away during that time..." (R18/M59). Finally, as mentioned earlier respondents also considered 24-hour institutional care to be an important aspect of senior policy. While for many respondents, at the given moment this would not be their preferred solution, they did mention that this tool must be made available. Respondents mentioned that these institutions should be available and that they should be affordable because sometimes there are situations where this option 
is the only possibility: "...I know some situations are such that people must have the option to leave their loved one in a full-time care facility, for example if the family is too far or can't provide care for whatever reason..." (R18/M59).

Within the second category we find a need for training and education to be provided to caregivers as well as emotional, psychological and social support. Respondents mentioned that they are willing to help and care for their parents but sometimes they simply don't know how to properly do so (this was especially true for male caregivers): “... a caregiver needs to know how to care for someone, so he needs to have some form of educational support, someone who will teach how to care..." (R5/M68). Respondents mentioned that it was hard to deal and react to parents with symptoms of dementia or other illnesses both physical and mental because they had no experience in the matter. On top of education and training it was also important for caregivers to be able to receive psychological, emotional support from professionals or simply to be able to talk to someone about their situation: "... support groups would definitely be necessary because people find out that they are not alone, that others are in the same situation and you can exchange experiences..." (R12/F63).

The third category encompasses actions and solutions directed at simplifying procedures for attaining tools. Many respondents mentioned that while they are aware of existing public policy tools which could help them in their caretaking role often the amount of paperwork and time consumed to apply for them was simply not something they could do: "...I tried to get a public caregiver once and when I saw what I had to do I didn't..." (R4/M50)". They mentioned that elders often had to visit doctors yet the line ups were very long, doctors were not properly trained, there was a lack of geriatric doctors and access to these services was difficult: “...we need more geriatric doctors so they know how to help elders..." (R8/F32). Respondents mentioned that this hardship was the case for both social services, as well as medical services and while public policy has to consider the specific types of tools and resources available it is also extremely important to make it easier and less time consuming to access them.

The fourth category was the most diverse and solutions were directed specifically at the wellbeing of elders which in turn was said to affect the wellbeing of caregivers. Respondents were aware that activities which promoted physical and mental health had a positive impact on their caregiving situation. Within this category the most popular was the idea that public policy should ensure activities for seniors, motivating them to keep mentally and physically active: "...it is important to activate the brain to work for elder people then the longer they are able to function in society...” (R8/F32). Providing in-home and outside rehabilitation services was also popular amongst respondents: “...we need rehabilitation services because elders are healthier physically and able to do more if they are rehabilitated..." (R1/F36). A common idea, was for governments or private companies to organize transportation services for elders as well as improve infrastructure: “...for me the hardest part is getting my mom to the doctor, I've done it before where I would just push her wheelchair down the street...” (R15/F57). While some elders where still mentally active they were unable to physically move which made them prisoners of their homes especially if 
caregivers where not equipped with the necessary equipment and vehicles. Furthermore, especially if elders lived in smaller areas, sometimes they required the time and help of their children for things that they theoretically could do themselves because of a lack of infrastructure and/or transportation possibilities for them to do these things on their own. Solutions and tools provided as examples, aside from providing transportation and infrastructure were: creating communities and/or special neighbourhoods dedicated for elders, telemedicine (because not every situation required a visit to the doctor), and/or electronic pulse monitoring (because many things can be achieved easily using today's technology).

Last but not least, financial aid was mentioned by respondents. Surprisingly enough even though quite a few respondents mentioned some form of financial strain related to care provision, financial aid in the form of different benefits did not seem to be the predominant form of help they expected or thought was the best solution. Most respondents who in some way favoured financial tools were more likely to say funding should be made available for things like day care, 24-hour institutional care and/or outside caregivers: "... supplementary payments for care facilities so that people could afford them..." (R7/F41), “... a division of the costs of caregivers and institutions...” (R14/F55), “...funding for hygiene products because they cost a lot...” (R12/F63), “...more medications that could be funded, they are expensive..." (R19/F41). Respondents often mentioned the fact that the pension of their care recipient was very low and didn't cover basic daily needs: "...I wish my mom had enough pension for me not to have to worry about not being able to afford her care..." (R17/F60).

Overall, respondents agreed on the idea that everyone's situation is different and different approaches should be considered. When asked about the ideal solution respondents realized that there was no single answer. Many noticed that while providing care is definitely not an easy task, and there is definitely not enough being done to help them, they also had trouble answering what ideally should be offered. Respondents were also aware that the more diverse the array of tools and solutions available the better. Additionally, there could be solutions which could be costlier but not suitable for everyone. For example, if someone is completely against the idea of placing their parents in a full-time institution, no matter how many of these institutions will become available and whatever their price be they simply will not take advantage of such a solution.

\section{Discussion and Conclusion}

The effect of caregiving on SWB is very complex. While caregiving may bring satisfaction and reward in some situations (Quinn et al., 2010) for many caregivers it is a stressful experience (Pot et al., 1997; Hajek \& Konig, 2016; Niimi, 2016). Furthermore, SWB is not without flaws and its main criticism is hedonic adaptation; measures of SWB may not be accurate because people have the ability to adapt to poor conditions and negative life situations (Graham, 2009). As mentioned earlier, for cultural reasons, and as a result of the limited availability of professional caregivers, the predominant form 
of care for elders in Poland has been and still is, care provided informally by family members (Bakalarczyk, 2018), there exists a well-established norm that it is the family who should provide care and perhaps the Polish population is experiencing hedonic adaptation. However, while simply being an informal parent's caregiver seemed not to be important for individual's evaluations of SWB, there were many characteristics, as also shown by other studies related to the care situation (Shakeel et al., 2015; Niimi, 2016; Rafnsson et al., 2017; Verbakel et al., 2018) which respondents said did affect their SWB. Respondents mentioned that the time caretaking consumed, the lack of institutional support or support from other family members, mental (especially symptoms related to dementia) and physical health characteristics of the care recipient and difficulties accessing health and social resources were something that affected their SWB.

Amongst the characteristics mentioned above the two most important, reoccurring and overreaching factors that seemed to be affecting the SWB of parent's caregivers were time and dementia. Many respondents mentioned that caretaking consumed not only, any free time they had but also, time available for other responsibilities, hobbies, needs and rest. Difficult or non-existent access to outside help, support and healthcare resulted in a lack of (free) time experienced by respondents; a lack of (free) time seemed to be the most common explanation of the negative effects of caretaking on SWB. Respondents mentioned that they had to give up spending time with other family members or friends, that they were not able to go out, that they had to give up sports, that they didn't have time to care about their own health and many more. This is extremely important because it means that caretaking affected their ability to achieve those VFs. How can someone pursue passions and hobbies or stay healthy if they don't have the time to do so?

However, caring for parents could also positively affect wellbeing and respondents often said that caring for their parents contributed to a higher SWB and/or positive feelings. Social network size and the quality and quantity of positive interpersonal relationships has a positive relationship with SWB levels (Wang, 2014; Li, 2016). This means that the bond between children and parents (especially if they were mentally healthy and not experiencing dementia which hinders the ability to form meaningful bonds), the ability for intergenerational exchange of experiences and knowledge, the time spent together as well as the feeling of purpose and fulfillment could increase SWB levels. Here, the second aspect which caregivers said affected their SWB, dementia of the care recipient, which also seemed to have the strongest negative effect on the SWB of the caregiver severely affected the ability for a caregiver-care recipient bond; it caused elders to be out of touch with reality, to be unable to form meaningful bonds with others, as well as, to elicit aggressive behaviour. Based on respondents' answers, but specifically those whose parents didn't have dementia, it didn't seem that shifting the burden of care onto institutions would necessarily increase SWB of the caregiver. In general, respondents were more likely to mention that if they had the proper knowledge, resources and accessibility to the instruments they needed to provide care to their parents and generate some free time for themselves, their life satisfaction would be greater. Respondents valued the chance they had to spend time with their parents and mentioned that they felt good about being able 
to help because it gave them a sense of purpose, belonging and responsibility. If informal parent's caregivers receive the tools and support they need to be able to provide proper care and to be able to balance caring for their parents with other responsibilities and hobbies, then caretaking maybe would not decrease SWB of informal caregivers but it could actually have a positive impact on SWB levels.

People have preferences when it comes to providing care to parents and these preferences are significant for the SWB of informal caregivers. The solutions people prefer and expect from the government are neither fully familialistic nor fully de-familialistic and this generates the conclusion that public policy in Poland should head in the direction of optional familialism and tools and solutions offered to elders and their potential caregivers should be diverse. Providing only familialistic solutions could greatly affect the wellbeing of informal parent's caregivers whose care recipients have dementia. Providing only de-familialising tools, on the other hand, could counter the positive effects of caretaking. Furthermore, a support for optional familialism (Leitner, 2003), does not imply advocating "quantity over quality" because both are important. However, "quantity" is not only favourable because of the number of tools but because it allows individuals to choose what they prefer and this possibility can increase their wellbeing. The results of the study also indicated a need for policy instruments which would allow informal caregivers to attend to other responsibilities, needs and hobbies. Various instruments such as adequate day care institutions, respite care and most importantly reliable, accessible and on-call caregivers could provide tired and overworked caregivers with the opportunity to relax and achieve VFs that they could otherwise not achieve. The results of the study also showed, that not only did different instruments need to be available, they should be easy to use (to apply for) and of good quality. Often access to some of the tools available was difficult not only because of their limited nature but also due to the fact that the bureaucratic process was lengthy and required a lot of time (which was already limited due to care related responsibilities).

While optional familialism seems to be the obvious choice, an ideal society where absolutely every possible tool and solution is available is impossible. Policies are limited by financial resources and funds available for different tools and solutions. SWB measures, and understanding the situations of informal caregiver could guide policy in terms of which services are offered to which groups. To illustrate this, if we assume that dementia brings with it the most negative effects on caregiver SWB then priority in institutions should be given to patients with confirmed dementia. Offering cash benefits to someone who needs training on care provision will not be of any help, unless at the same time policy makers focus on creating paid training centres for informal caregivers. Similarly, 24-hour institutional care will not be an option for someone who knows that placing their parent/ elder in an institution will cause everyone distress. Even if such a facility is available while most may not take advantage of it will be an option for those unable and unwilling to provide care. While it may be reasonable to believe that full time facilities may completely unburden the family from care and in turn increase their SWB, perhaps an hour, a day or a week of free time for the caregiver may be enough to significantly increase their SWB. 
Summarizing, the most important results of this study 1) The subjective evaluation of SWB, in view of respondents' caretaking roles, is not only highly dependent on things such as the burden of care, the characteristics of the care recipient, the support the caregiver receives and the time spent caring but also in turn on the limitations caregiving imposes on caregiver ability to achieve beings and doings which they value. Additionally, all these things are highly interrelated and dependent on one another with a major connecting factor being time. 2) While many characteristics related to the caretaking situation negatively affect SWB there could be/are also aspects of the caregiving situation which can increase levels of SWB and with proper tools and solutions these positive aspects can be intensified. 3) Polish respondents have individual preferences when it comes to the types of help (tools and resources) they need and there is an agreement that various, flexible tools and an optional familialism regime, are needed and the needs are determined by the characteristics of individual situations.

\section{References}

Bakalarczyk, R. (2018). Polityka wsparcia nieformalnych opiekunów niesamodzielnych osób starszych. Na podstawie zmian prawnych $w$ latach 2003-2015. Wydawnictwo Uniwersytetu Warszawskiego.

Braun, V. \& Clarke, V. (2006). Using thematic analysis in psychology. Qualitative Research in Psychology, 3(2), 77-101.

Diener, E., Emmons, R. A., Larsen, R. J., \& Griffin, S. (1985). The Satisfaction with Life Scale. Journal of Personality Assessment, 49, 71-75.

European Commission. (2015). The Ageing Report: Economic and budgetary projections for the 28 European Member States (2013-2060), European Economy 3.

Graham, C. (2009). Happiness around the world. Oxford University Press.

Grochowska, J. (2014). Feeling of satisfaction and being burdened with duties among informal care givers of the elderly according to the level of efficacy of care recipients. Medycyna Ogólna i Nauki o Zdrowiu, 20(1), 46-50.

Hajek, A. \& Konig, H. H. (2016). Informal Caregiving and Subjective Well-Being: Evidence of a Population-Based Longitudinal Study of Older Adults in Germany. Journal of the American Medical Directors Association, 17(4), 300-305.

Katz, S., Down, T. D., Cash, H. R., \& Grotz, R. C. (1970). Progress in the development of the index of ADL. The Gerontologist, 10(1), 20-30.

Kurowska, A. (2018). (De)familialization and (De)genderization - competing or complementary perspectives in comparative policy analysis? Social Policy \& Administration, 52(1), 29-49.

Krzyżowski, Ł. (2011). In the Trap of Intergenerational Solidarity: Family Care in Poland's Ageing Society. Polish Sociological Review, 1(73), 55-78.

Lawton, M. P. \& Brody, E. M. (1969). Assessment of older people: Self-maintaining and instrumental activities of daily living. The Gerontologist, 9(3), 179-186. 
Lacey, R. E., McMunn, A., \& Webb, E. (2018). Informal caregiving patterns and trajectories of psychological distress in the UK Household Longitudinal Study. Psychological Medicine, 1(9).

Leitner, S. (2003). Varieties of familialism. The caring function of the family in comparative perspective. European Societies, 5(4), 353-375.

Li, Y. (2016). Social mobility, social network and subjective well-being in the UK. Journal of the Academy of Social Sciences, 11(2-3), 222-237.

Mason, M. (2010). Sample Size and Saturation in PhD Studies Using Qualitative Interviews. Forum Qualitative Sozialforschung, 11(3), 1-20.

Niimi, Y. (2016). The "Cost" of informal care: an analysis of the impact of elderly care on caregivers' subjective well-being in Japan. Review of Economics of the Household, 14(4), 779-810.

O'Neill, G. \& Ross, M. M. (1991). Burden of Care: An important Concept for Nurses. Health Care Women Int., 12(1), 111-121.

Perek-Białas, J. \& Stypińska, J. (2010). Łączenie pracy i opieki nad osobą starszą — wpływ na jakość życia opiekuna. In D. Kałuża, P. Szukalski (red.), Jakość życia seniorów w XXI wieku. Ku Aktywności. (136-148). Uniwersytet Łódzki.

Pot, A. M., Deeg, D. J. H., \& Van Dyck, R. (1997). Psychological well-being of informal caregivers of elderly people with dementia: Changes over time. Aging \& Mental Health, $1(3), 261-268$.

Quinn, C., Clare, L., \& Woods, R. T. (2010). The impact of motivations and meanings on the wellbeing of caregivers of people with dementia: a systematic review. International Psychogeriatrics, 22(1), 43-55.

Rafnsson, S. B., Shankar, A., \& Steptoe, A. (2017). Informal caregiving transitions, subjective well-being and depressed mood: Findings from the English Longitudinal Study of Ageing. Aging and Mental Health, 21(1), 104-111.

Robeyns, I. (2006). The Capability Approach in Practice. The Journal of Political Philosophy, 14(3), 351-376.

Saraceno, C. \& Keck, W. (2010). Can we identify intergenerational policy regimes in Europe? European Societies, 12, 675-696.

Sen, A. (1983). Poor, Relatively Speaking. Oxford Economic Papers, 35(2), 153-169.

Sen, A. (1999). Development as Freedom. Knopf.

Shakeel, S., Rana, S. A., \& Malik, N. I. (2015). Burden of Care, Mental Health and Subjective Well Being of Family Caregivers of Elderly Patients. Pakistan Journal of Professional Psychologists, 6(1), 1-16.

Ślusarska, B., Bartoszek, A., Kocka, K., Deluga, A., Chrzan-Rosak, A., \& Nowicki, G. (2019). Quality of life predictors in informal caregivers of seniors with a functional performance deficit - an example of home care in Poland. Clinical Interventions in Aging, 14, 889-903.

Stojak, Z., Jamiołkowski, J., Chlabicz, S., \& Marcinowicz, L. (2019). Levels of Satisfaction, Workload Stress and Support Amongst Informal Caregivers of Patients Receiving or 
Not Receiving Long-Term Home Nursing Care in Poland: A Cross-Sectional Study. International Journal of Environmental Research and Public Health, 16(7), 1189-1198.

Verbakel, E., Metzelthin, S. F., \& Kempen, G. I. J. M. (2018). Caregiving to Older Adults: Determinants of Informal Caregivers' Subjective Well-being and Formal and Informal Support as Alleviating Conditions. The journals of gerontology. Series B, Psychological sciences and social sciences, 14: 73(6), 1099-1111.

Van den Berg, B., Fiebig, D. G., \& Hall, J. (2014). Well-being losses due to care-giving. Journal of Health Economics, 35(100), 123-131.

Wang, X. (2014). Subjective well-being associated with size of social network and social support of elderly. Journal of Health Psychology, 21(6), 1037-1042.

Wizner, B., Skalska, A., Klich-Rączka, A., Piotrowicz, K., Grodzicki, T. (2012). Stan zdrowia i sprawność osób starszych. In M. Mossakowska, A. Więcek, P. Błędowski (red.), PolSenior. Aspekty medyczne, psychologiczne i ekonomiczne starzenia się ludzi w Polsce. (82-83). Termedia. 